\title{
Prevalence of Metabolic Syndrome and Its Clinical and Angiographic Profile in Patients With Naive Acute Coronary Syndrome in North Indian Population
}

\author{
Santosh Kumar Sinha ${ }^{\mathrm{a}, \mathrm{b}}$, Amit Goel ${ }^{\mathrm{a}}$, Amit Madaan ${ }^{\mathrm{a}}$, Ramesh Thakur ${ }^{\mathrm{a}}$, Vinay Krishna ${ }^{\mathrm{a}}$, Karandeep Singh ${ }^{\mathrm{a}}$, \\ Mohit Sachan ${ }^{a}$, Umeshwar Pandey ${ }^{\mathrm{a}}$, Chandra Mohan Varma ${ }^{\mathrm{a}}$
}

\begin{abstract}
Background: Data of isolated metabolic syndrome as risk factor in patients presenting with acute coronary syndrome (ACS) especially in context to Indian subcontinent are sparse. Therefore, we studied the prevalence of metabolic syndrome (MetS), and its clinical and angiographic profile in naive ACS patients in North Indian population.
\end{abstract}

Methods: A single-center, prospective, observational study of 324 patients was conducted at LPS Institute of Cardiology, G.S.V.M. Medical College, Kanpur, India with newly diagnosed ACS patients with MetS, as per modified NCEP-ATP III criteria. They were divided into two groups with and without MetS, and their clinical and angiographic profiles were studied.

Results: Prevalence of MetS in our study was $37.65 \%$. Patients with MetS were significantly older than without MetS $(60.3 \pm 8.4$ vs. $57.6 \pm 7.9)$, and had females preponderance $(35.24 \%$ vs. $24.25 \%)$, less tobacco abuse (30.32\% vs. $42.57 \%)$, more non-ST-segment elevation ACS (58.19\% vs. 36.14\%), less ST-segment elevation myocardial infarction (STEMI) (41.80\% vs. 63.86\%), more cardiogenic shock $(27.04 \%$ vs. $17.32 \%)$, recurrent ischemia $(14.75 \%$ vs. $7.42 \%)$ and on angiogram, lesser single vessel disease (21.13\% vs. $53.96 \%)$, more double vessel disease (39.34 vs. $24.26 \%$ ), triple vessel disease (19.67\% vs. $10.39 \%)$, left main (13.11\% vs. $4.45 \%)$ and complex coronary lesions (tubular $40.98 \%$ vs. $31.68 \%$; diffuse $26.23 \%$ vs. $18.32 \%)$. However, there was a trend of lower but insignificant mortality with MetS (5.44\% vs. $6.55 \%)$.

Conclusion: There was high prevalence of MetS among patients with ACS in North Indian population with more advanced coronary artery disease. To the best of our knowledge, this is the first study from North India documenting clinical and angiographic profile of patients

Manuscript accepted for publication July 18, 2016

a Department of Cardiology, LPS Institute of Cardiology, G.S.V.M. Medical College, Kanpur, Uttar Pradesh 208002, India

${ }^{b}$ Corresponding Author: Santosh Kumar Sinha, Department of Cardiology, LPS Institute of Cardiology, G.S.V.M. Medical College, Kanpur, Uttar Pradesh 208002, India. Email: fionasan@rediffmail.com

doi: http://dx.doi.org/10.14740/jocmr2655w with MetS and ACS.

Keywords: Acute coronary syndrome; Complex lesion; Coronary artery disease; Metabolic syndrome; Single vessel disease

\section{Introduction}

Worldwide, the metabolic syndrome (MetS) is a major health problem associated with increased morbidity and mortality from cardiovascular disease (CVD). MetS is a conglomerate of various risk factors which is known to increase the risk for development of CVD. Various terms which have been ascribed for this constellation of findings are syndrome X, insulin resistance syndrome, "deadly quartet" and obesity dyslipidemia syndrome $[1,2]$. MetS represents a group of cardiovascular risk factors, including hyperglycemia, elevated blood pressure (BP), elevated triglyceride (TG) levels, central obesity and decreased high-density lipoprotein cholesterol (HDL-C) [3]. It will exacerbate the progression of CVD if left untreated. The estimates of the prevalence of MetS ranged from $21.3 \%$ to $32.8 \%$ among the participants in the Framingham Offspring Study and San Antonio Heart Study [4]. There are limited data available on the prevalence of MetS in Indian population because of varied extent of urbanization, lifestyle patterns, and socioeconomic/cultural factors. Also western studies suggest that MetS is very commonly associated with coronary artery disease (CAD), but little is known about the prevalence of MetS in patients with acute coronary syndrome (ACS) in Indian subcontinent. Hence, our study aimed to ascertain the prevalence of MetS and its clinical and angiographic profile in patients with naive ACS in North Indian population.

\section{Materials and Methods}

\section{Study design and patients}

Our study was a single-center, observation study which prospectively enrolled 324 patients with naive ACS during the time period from January 2014 to June 2015 in Department of 
Table 1. Baseline Characteristics of Patients $(n=648)$

\begin{tabular}{llll}
\hline Characteristics & MetS $(\mathbf{n}=\mathbf{2 4 4})$ & No MetS $(\mathbf{n}=\mathbf{4 0 4})$ & P-value \\
\hline Age (years) & $60.3 \pm 8.4$ & $57.6 \pm 7.9$ & 0.07 \\
Female & $86(35.24 \%)$ & $98(24.25 \%)$ & 0.04 \\
Diabetes mellitus & $114(46.72 \%)$ & $88(21.78 \%)$ & $<0.001$ \\
Hypertension & $154(63.11 \%)$ & $134(33.16 \%)$ & $<0.001$ \\
Family history of CAD & $58(23.77 \%)$ & $92(22.7 \%)$ & 0.43 \\
Abdominal obesity & $116(47.54 \%)$ & $90(22.27)$ & 0.005 \\
Tobacco abuse & $74(30.32 \%)$ & $172(42.57 \%)$ & $<0.001$ \\
BMI (kg/m $\left.{ }^{2}\right)$ & $31.6 \pm 3.4$ & $25.2 \pm 2.8$ & 0.01 \\
Serum HDL-C (mg/dL) & $32.7 \pm 5.9$ & $41.6 \pm 4.8$ & 0.005 \\
Serum TG (mg/dL) & $228.6 \pm 56.3$ & $132.3 \pm 38.5$ & 0.006 \\
STEMI & $102(41.80 \%)$ & $258(63.86 \%)$ & 0.002 \\
NSTEACS & $142(58.19 \%)$ & $146(36.14 \%)$ & 0.003 \\
Cardiogenic shock & $66(27.04 \%)$ & $70(17.32 \%)$ & 0.02 \\
Ejection fraction $(\%)$ & $47.3 \pm 8.2$ & $50.35 \pm 6.5$ & 0.11 \\
Recurrent ischemia & $36(14.75 \%)$ & $30(7.42 \%)$ & 0.01 \\
Mortality & $8(6.55 \%)$ & $11(5.44 \%)$ & 0.23 \\
\hline
\end{tabular}

Cardiology at LPS Institute of Cardiology, Kanpur (India). The study received ethical approval from the institutional ethical body. Informed and written consent was obtained from all participants. The inclusion criteria met were age $>18$ years and first episode of ACS. The diagnosis of ACS was made in the presence of serial increase of cardiac biomarkers, associated with typical electrocardiogram changes and/or typical symptoms, as defined by the Joint Committee of the American College of Cardiology [5]. Patients with ST-segment elevation or new left bundle branch block on the admission electrocardiogram were diagnosed with ST-segment elevation myocardial infarction (STEMI). The remaining patients were categorized as having non-ST-segment elevation ACS (NSTEACS) [5]. We excluded the patients with prior CAD or who underwent coronary artery bypass graft/percutaneous coronary intervention. Also the patients with liver or kidney chronic disease, neoplasm, acute infections or surgical intervention in last 6 weeks were excluded.

Although there are several definitions of MetS, the diagnosis of MetS in the cohort was based on the criteria defined by modified NCEP-ATP III guidelines: [6] 1) waist circumference ( $\geq 90 \mathrm{~cm}$ in men and $\geq 80 \mathrm{~cm}$ in women); 2) SBP $\geq 130 \mathrm{~mm} \mathrm{Hg}$ and/or DBP $\geq 85 \mathrm{~mm} \mathrm{Hg}$ or medical treatment of previously diagnosed hypertension; 3 ) triglyceride $(\mathrm{TG})>150 \mathrm{mg} / \mathrm{dL}(1.7$ $\mathrm{mmol} / \mathrm{L})$; 4) HDL-C $<40 \mathrm{mg} / \mathrm{dL}(1.03 \mathrm{mmol} / \mathrm{L})$ in men, $<50$ $\mathrm{mg} / \mathrm{dL}(1.29 \mathrm{mmol} / \mathrm{L})$ in women; 5) fasting glucose $>110 \mathrm{mg} /$ dL. Presence of any three or more defined MetS.

The waist circumference was measured on admission, midway between the last rib and iliac crest and the average of three measures was recorded [7]. The body mass index (BMI) was measured as the ratio between the weight $(\mathrm{kg})$ and the square of height $\left(\mathrm{m}^{2}\right)$, according to the international criteria. Pertinent medical, family (premature CAD at age $<55$ and $<$
65 years in male and female first degree relatives, respectively) and social (smoking and alcohol consumption) histories were obtained for each patient. Systolic blood pressure (SBP) and diastolic blood pressure (DBP) were measured thrice at an interval of $3 \mathrm{~min}$ in the sitting position after a 15 min rest and the mean was taken. Blood samples $(3 \mathrm{~mL})$ were drawn after 8 - $12 \mathrm{~h}$ of overnight fasting for the measurement of lipid profile (total cholesterol, HDL-C and TG) and fasting plasma glucose levels. Plasma glucose was measured using the glucose oxidase peroxidase method [8], serum total cholesterol [9] and TG [10] by standard enzymatic procedures and HDL-C [11] by direct assay method. Echocardiography was performed for evaluation of ejection fraction (EF\%) according to the clinical standards and in accordance with recommendation related to current echocardiography guidelines [12]. All patients underwent coronary angiography by standard technique on a monoplane system as recommended in current guidelines to define the coronary anatomy and severity of epicardial CAD. Number and type of coronary vessel involved along with the lesion characteristics in the two groups (MetS vs. no MetS) were studied. Lesions were classified into discrete $(<10 \mathrm{~mm}$ in length), tubular (10 - $20 \mathrm{~mm}$ in length) and diffuse $(>20 \mathrm{~mm}$ in length) as per ACC/AHA classification [13]. More than 50\% diameter stenosis of any single coronary artery was considered significant disease.

\section{Statistical analysis}

Statistical analysis was performed by using the Statistical Package for Social Sciences version 17 (SPSS Inc., Chicago, IL). Nominal (categorical) variables were analyzed by using Pearson Chi-square test or Fischer's exact test and quantitative 
Prevalence of individual components of Metabolic Syndrome

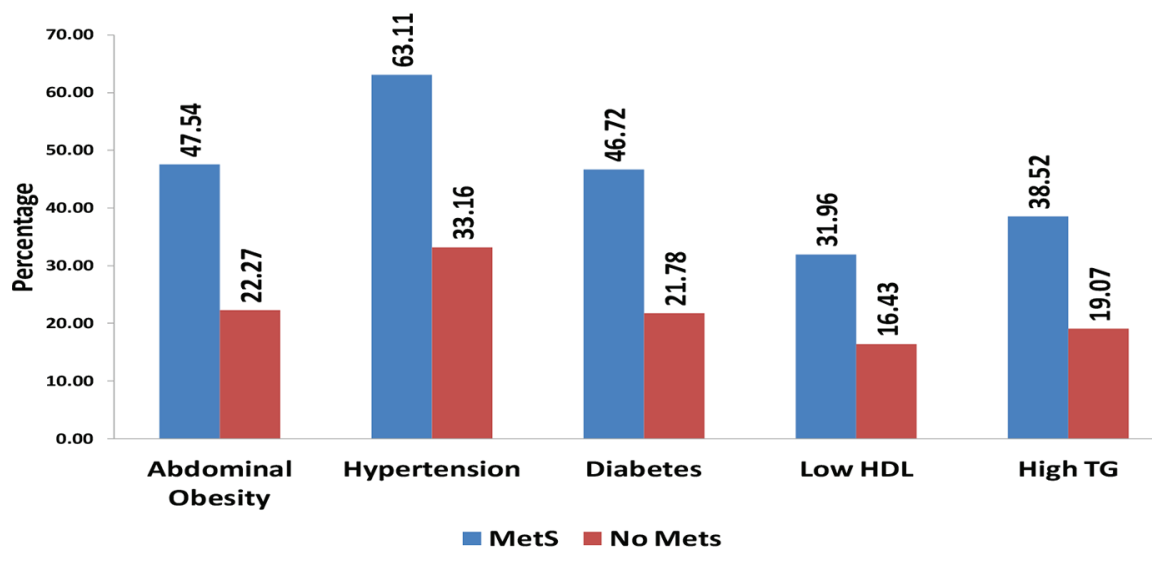

Figure 1. Prevalence of individual components of metabolic syndrome.

variables by using Mann-Whitney test or unpaired $t$-test. A P $<$ 0.05 was considered statistically significant.

\section{Results}

The overall prevalence of MetS in our study was $37.65 \%(\mathrm{n}=$ 244). The mean age of 648 patients included in the study was $58.68 \pm 5.6$ years, with the preponderance of men $(n=464$; $71.6 \%$ ). Table 1 summarizes the baseline characteristics of the cohort with and without MetS. From the total study cohort, 244 patients $(37.65 \%)$ therefore fulfilled the criteria for MetS according to modified NCEP-ATP III guidelines. The prevalence of the individual components of MetS was $47.54 \%$ (n $=116)$ for abdominal obesity, 63.11\% $(n=154)$ for hypertension, $46.72 \%(\mathrm{n}=114)$ for diabetes mellitus, $31.96 \%(\mathrm{n}=$ 68 ) for low HDL-C, and $38.53 \%(n=94)$ for high TG levels. Graphical representation of individual component in each group is shown in Figure 1.

The combination of HDL-C $(<40 \mathrm{mg} / \mathrm{dL})$ and TG $(>150$ $\mathrm{mg} / \mathrm{dL})$ represents the "atherogenic dyslipidemia" was present in $28.68 \%(\mathrm{n}=70)$ of the patients with MetS and in $17.82 \%$ (n $=72$ ) of those without MetS $(\mathrm{P}<0.05)$. Overall, MetS patients with ACS were 2.7 years older than those without MetS, more likely to be females (35.24\% vs. $24.25 \%)$ and less likely to be tobacco abuser (30.32\% vs. 42.57\%). Patients with MetS were more likely to present with NSTEACS (58.19\% vs. $36.14 \%$, $\mathrm{P}=0.003)$ than STEMI (41.8\% vs. $63.86 \%, \mathrm{P}=0.002)$. MetS patients had more chance of cardiogenic shock $(27.04 \%$ vs. $17.32 \%, \mathrm{P}=0.02)$ and recurrent ischemia ( $14.75 \%$ vs. $7.42 \%$, $\mathrm{P}=0.01)$. There was no statistically significant difference of EF as well as mortality between groups.

The baseline angiographic characteristic of study population is depicted in Table 2. The angiographic profile revealed lower preponderance of single vessel disease (SVD) in MetS group vis-a-vis without MetS group $(21.13 \%$ vs. $53.96 \%$, P

Table 2. Baseline Angiographic Characteristics of Patients $(n=648)$

\begin{tabular}{|llll}
\hline Characteristics & MetS $(\mathbf{n}=\mathbf{2 4 4})$ & No MetS $(\mathbf{n}=\mathbf{4 0 4})$ & P-value \\
\hline Angiographic profile of CAD & & & \\
$\quad$ Recanalized & $14(5.73 \%)$ & $28(6.94 \%)$ & 0.001 \\
SVD & $54(21.13 \%)$ & $218(53.96 \%)$ & 0.001 \\
DVD & $96(39.34 \%)$ & $98(24.26 \%)$ & 0.001 \\
TVD & $48(19.67 \%)$ & $42(10.39 \%)$ & 0.001 \\
\hline LMCA & $32(13.11 \%)$ & $18(4.45 \%)$ & 0.001 \\
Lesion characteristics* & & & \\
Type A & $80(32.78 \%)$ & $202(50 \%)$ & 0.01 \\
Type B & $100(40.98 \%)$ & $128(31.68 \%)$ & 0.01 \\
\hline Type C & $64(26.23 \%)$ & $74(18.32 \%)$ & 0.01 \\
\hline
\end{tabular}

SVD: single vessel disease; DVD: double vessel disease; TVD: triple vessel disease; LMCA: left main coronary artery. *Lesion characteristics based on ACC/AHA Subcommittee for Percutaneous Transluminal Coronary Angioplasty. 


\section{Baseline Angiographic Characteristics}

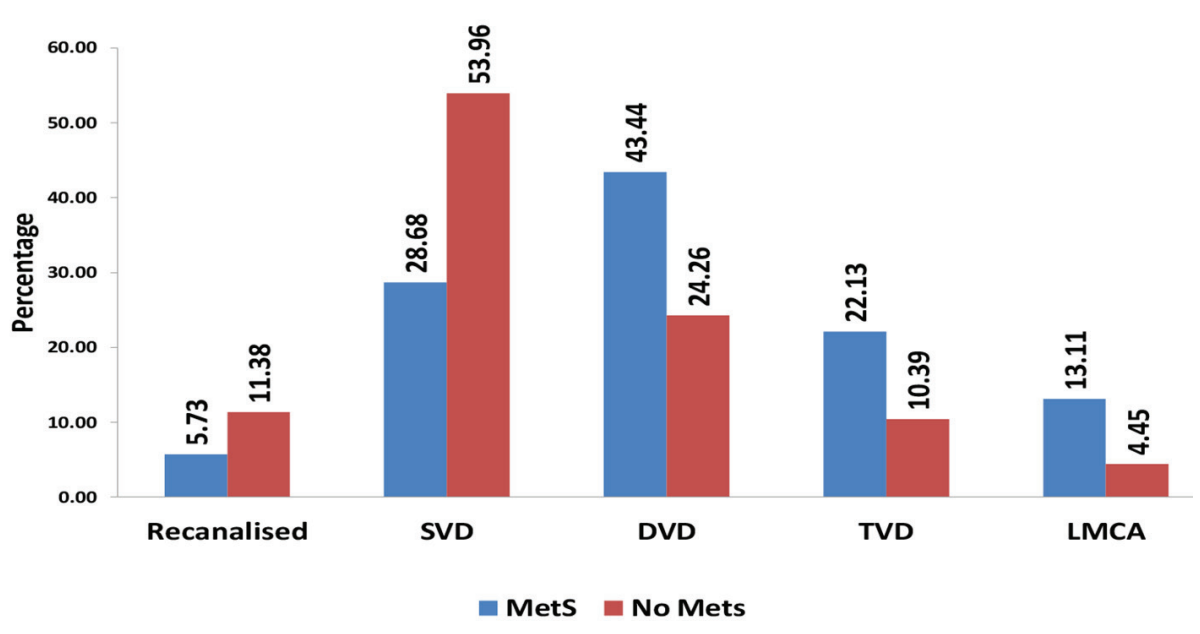

Figure 2. Baseline angiographic characteristics of patients.

$=0.001)$. However, presence of involvement of more than one vessel, i.e., doubles vessel disease (DVD) and triple vessel disease (TVD), was $39.34 \%$ vs. $24.26 \%$ and $19.67 \%$ vs. $10.39 \%$, respectively $(\mathrm{P}=0.001)$. Left main coronary artery (LMCA) disease was found more common in MetS population than without MetS population (13.11\% vs. 4.45\%, $\mathrm{P}=0.001)$. More complex coronary lesions (tubular, $40.98 \%$ vs. $31.68 \%$ and diffuse, $26.23 \%$ vs. $18.32 \%, \mathrm{P}=0.01)$ were common in MetS group than in patients without MetS group, whereas simple coronary lesions (discrete, $32.78 \%$ vs. $50 \%, \mathrm{P}=0.01$ ) were found to be more in no MetS patient group. The angiographic profiles of two study groups are depicted in Figure 2. Total number of patients who underwent coronary intervention during index admission was $55.86 \%(\mathrm{n}=181)$ in both groups.

\section{Discussion}

MetS is a major public health problem of 21 st century. It is the conglomerate of physical conditions and metabolic abnormalities occurring together that increases an individual risk for development of type 2 diabetes mellitus and CVD. If the trend of MetS continues to increase, the premature deaths and disabilities resulting from it will pose an increase of the financial and social burden in both developed and developing countries. Numerous definitions have been proposed in the past by various expert groups for the MetS. In 1998, World Health Organization (WHO) defined MetS, according to which a person must have either glucose intolerance or insulin resistance with two of the following four criteria: central obesity, hypertension, dysplipidemia and albuminuria. In 2001, National Cholestrol Education Program Adult Treatment Panel III (NCEP-ATP III) provided a new definition for MetS, which states that a person must have three of the following five abnormalities: abdominal adiposity, hypertension, hypertriglyceridemia, low HDL-C, and elevated fasting glucose. WHO consultation in
2004 was of opinion that the proportion of Asian people with high risk of type 2 diabetes mellitus and CVD is considerable at BMI values lower than the existing WHO cutoff point for overweight $\left(25.0 \mathrm{~kg} / \mathrm{m}^{2}\right)$ and proposed potential public health action points of BMI $\left(23.0,27.5,32.5\right.$, and $\left.37.5 \mathrm{~kg} / \mathrm{m}^{2}\right)$ but did not suggest a clear BMI cutoff point for overweight and obesity [14]. Despite a considerable evidence of the same fact, none of expert committee group were able to define lower BMI cutoff for Asian subset. Contrary to BMI cutoff, consensus has been reached regarding lowering waist circumference cutoff $\geq$ $90 \mathrm{~cm}$ in males and $\geq 80 \mathrm{~cm}$ in females in south Asians based on adequate evidence, which has henceforth been adopted in the modified NCEP-ATP III [6] and IDF definitions [13]. Table 3 summarizes various diagnostic criteria for defining MetS.

Overall, the prevalence of MetS in our study was $37.65 \%$. Using NCEP-ATP III criteria, Suwaidi et al [15] found MetS in $46 \%$ of ACS. However, Danciu et al [16] and Pandey et al [17] reported 26\% and 26.19\% prevalence of MetS in ACS. These data further support the causation of CVD in patients with MetS. Patients with MetS were 3 years older than without MetS. Similar finding was observed by Yasar et al [18] and Dohi et al [19]. It was also found in our study that the prevalence of MetS in female patients who present with ACS was higher when compared with overall cohort. Studies done by Suwaidi et al [15], Gupta et al [20] and Ramachandran et al [21] had shown higher prevalence of MetS in female presenting with ACS.

Among the individual components of MetS, hypertension and abdominal obesity were more common. A high prevalence of diabetes mellitus (31.17\%) was seen in our study when compared with previous reports of Prasad et al (19\%) [22]. However, it extends the observation of Takeno et al [23] from Japan (34\%). Consumption of tobacco in any form was quite prevalent in our study $(37.96 \%)$ due to socio-cultural background. But it was seen that tobacco abuse was less prevalent in MetS group (30.32\%) than in no MetS group (42.57\%). It 
Table 3. Various Criteria Proposed for Metabolic Syndrome

\begin{tabular}{|c|c|c|c|}
\hline Criteria & Modified WHO & NCEP-ATP III (2001) & Modified NCEP-ATP III (2004) \\
\hline & $\begin{array}{l}\text { DM, IGT, IFG or insulin resistance } \\
\text { with } \geq 2 \text { of the following }\end{array}$ & $\geq 3$ of the following & $\geq 3$ of the following \\
\hline FPG (mg/dL) & & $>110$ & $>110$ \\
\hline Obesity & $\begin{array}{l}\mathrm{BMI}>30 \mathrm{~kg} / \mathrm{m}^{2} \text { or WHR }>0.9 \\
\text { for men and }>0.85 \text { for men }\end{array}$ & $\begin{array}{l}\text { Waist circumference }>102 \mathrm{~cm} \\
\text { in men and }>88 \mathrm{~cm} \text { in women }\end{array}$ & $\begin{array}{l}\text { Waist circumference }>90 \mathrm{~cm} \text { in } \\
\text { men and }>80 \mathrm{~cm} \text { in women }\end{array}$ \\
\hline $\mathrm{BP}(\mathrm{mm} \mathrm{Hg})$ & $\geq 140 / 90$ or on medication & $\begin{array}{l}\mathrm{SBP}>130 \text { and/or } \mathrm{DBP}>85 \text { or } \\
\text { medical treatment of previously } \\
\text { diagnosed hypertension }\end{array}$ & $\begin{array}{l}\mathrm{SBP}>130 \text { and/or } \mathrm{DBP}>85 \text { or } \\
\text { medical treatment of previously } \\
\text { diagnosed hypertension }\end{array}$ \\
\hline $\mathrm{TG}(\mathrm{mg} / \mathrm{dL})$ & $>150(1.7 \mathrm{mmol} / \mathrm{L})$ & $>150(1.7 \mathrm{mmol} / \mathrm{L})$ & $>150(1.7 \mathrm{mmol} / \mathrm{L})$ \\
\hline $\begin{array}{l}\text { HDL-C } \\
(\mathrm{mg} / \mathrm{dL})\end{array}$ & $\begin{array}{l}<35(0.9 \mathrm{mmol} / \mathrm{L}) \text { for men and } \\
39(1.0 \mathrm{mmol} / \mathrm{L}) \text { for women }\end{array}$ & $\begin{array}{l}<40(1.03 \mathrm{mmol} / \mathrm{L}) \text { in men and } \\
<50 \text { in women }(1.29 \mathrm{mmol} / \mathrm{L})\end{array}$ & $<40$ in men and $<50$ in women \\
\hline
\end{tabular}

BP: blood pressure; FPG: fasting plasma glucose; TG: triglyceride; HDL-C: high-density lipoprotein cholesterol.

supports the observation of Zeller [24] and colleagues.

BMI was higher in patients who had MetS. South Asian population is found to be phenotypically distinct from Caucasians when studied in context of MetS, in form of lower BMI, waist circumference and muscle mass. South Asian adults have hyperglycemia, hypertension and hypertriglyceridemia at lower levels of BMI and waist circumference [14, 25-28]. "Athergenic dyslipidemia" is common in South Asians who have low HDL-C and higher levels of small dense LDL when compared to Caucasians [29, 30]. NSTEACS as a presentation was found to be more common than STEMI in MetS group (58.19\% vs. $41.80 \%$ ), whereas STEMI was more common than NSTEACS in no MetS group (63.86\% vs. 36.14\%). Cardiogenic shock during hospitalization was frequent in MetS group. This finding was in accordance with Babic et al [30]. Recurrent ischemia was common in subset of MetS. Suwaidi et al [15] also found recurrent ischemia to be more common in MetS group which was statistically significant. Though LVEF (\%) was lower in patients with MetS subset, the statistical significance was not seen in our study. A statistically significant difference in mortality in both groups was not present. This extends the observation made by Suwaidi et al [15], Babic et al [30] and Pandey et al [17].

The type of vessel involved and the lesion characteristics in the two groups (Mets vs. no MetS) were studied. It was observed that SVD was more prevalent in no MetS group. However, DVD and TVD were more common in patients with MetS. Involvement of LMCA was commonly detected in MetS group than without MetS group. More complex coronary lesions (tubular and diffuse) were discerned in MetS group, whereas simple coronary lesions (discrete) were commonly seen in no MetS subgroup. The findings of coronary angiography of our study were in accordance with observations noted by Pattnaik et al [31] and Henry et al [32]. MetS patients have a higher incidence of multivessel disease involvement as per western literature [33-36].

The mechanisms by which MetS increases CVD risk remains poorly understood, but given the clear associations between the two, it probably directly influences atherosclerotic development, progression and instability. There are varied propositions regarding mechanistic considerations linking
MetS and atherosclerosis. The principle vascular perturbations linked to MetS include endothelial vasomotor dysfunction, vascular effects of advanced glycation end products, adverse effects of circulating free fatty acids (FFAs), and increased systemic inflammation. Endothelial vasomotor dysfunction, a hallmark of vascular disease in MetS, is associated with adverse CVD outcomes. The myriad mechanisms contributing to endothelial dysfunction include abnormal nitric oxide biology, increased endothelin and angiotension II, and reduced prostacyclin activity, all of which contribute to abnormal control of blood flow. In the setting of ACS events, the no reflow phenomenon after percutaneous intervention reflecting acute endothelial dysfunction occurs more commonly in the presence of MetS, resulting in large infarcts, increased arrhythmias and worse systolic function. Abnormalities in the coagulation and fibrinolytic pathways and in platelet biology add to the vascular risk MetS, yielding a constitutive prothrombotic milieu. These abnormalities include increased circulating tissue factor, factor VII, von Willebrand factor, and plasminogen activating inhibitor 1, with decreased levels of antithrombin III and protein C. In addition, disturbances of platelet activation, aggregation, morphology and lifespan further contribute to increased thrombotic potential, as well as to the acceleration of atherosclerosis. Lastly, increased systemic inflammation, increased oxidative stress and a lipid rich atherosclerotic plaque are thought to accelerate atherosclerosis and worsen CVD outcomes.

\section{Conclusion}

High prevalence $(37.65 \%)$ of MetS among patients with ACS in North Indian population was identified. Also there is trend of more advanced vascular damage (depending on number of vessel and type of lesion involved) in patients with MetS than those without MetS. To the best our knowledge, this is the first study from North India documenting the angiographic profile of patients with MetS and ACS. As the prevalence of MetS is high worldwide and increasing day by day due to sedentary lifestyle, the finding on our study has robust implications for its early diagnosis and appropriate intervention before devel- 
opment of its harmful consequences. To further expand current observation of ours, additional large-scale double-blinded randomized studies are urgently needed with new definition of MetS in context to Asian population.

\section{Limitation of study}

The limitation of the study was that the data were collected from an observational study. The fundamental limitation of observational studies cannot be eliminated because of the nonrandomized nature and unmeasured confounding factors.

\section{Disclosures}

None.

\section{Conflicts of Interest}

None.

\section{References}

1. Eckel RH, Grundy SM, Zimmet PZ. The metabolic syndrome. Lancet. 2005;365(9468):1415-1428.

2. Grundy SM, Brewer HB, Jr., Cleeman JI, Smith SC, Jr., Lenfant C. Definition of metabolic syndrome: Report of the National Heart, Lung, and Blood Institute/American Heart Association conference on scientific issues related to definition. Circulation. 2004;109(3):433-438.

3. Zimmet P, Magliano D, Matsuzawa Y, Alberti G, Shaw J. The metabolic syndrome: a global public health problem and a new definition. J Atheroscler Thromb. 2005;12(6):295-300.

4. Meigs JB, Wilson PW, Nathan DM, D'Agostino RB, Sr., Williams K, Haffner SM. Prevalence and characteristics of the metabolic syndrome in the San Antonio Heart and Framingham Offspring Studies. Diabetes. 2003;52(8):2160-2167.

5. Antman EM, Anbe DT, Armstrong PW, Bates ER, Green LA, Hand M, Hochman JS, et al. ACC/AHA guidelines for the management of patients with ST-elevation myocardial infarction: a report of the American College of Cardiology/American Heart Association Task Force on Practice Guidelines (Committee to Revise the 1999 Guidelines for the Management of Patients with Acute Myocardial Infarction). Circulation. 2004;110(9):e82-292.

6. Heng D, Ma S, Lee JJ, Tai BC, Mak KH, Hughes K, Chew SK, et al. Modification of the NCEP ATP III definitions of the metabolic syndrome for use in Asians identifies individuals at risk of ischemic heart disease. Atherosclerosis. 2006;186(2):367-373.

7. Poirier P, Giles TD, Bray GA, Hong Y, Stern JS, Pi-Sunyer FX, Eckel RH. Obesity and cardiovascular disease: pathophysiology, evaluation, and effect of weight loss: an update of the 1997 American Heart Association Scientific Statement on Obesity and Heart Disease from the Obesity Committee of the Council on Nutrition, Physical Activity, and Metabolism. Circulation. 2006;113(6):898-918.

8. Trinder P. Determination of blood glucose using an oxidase-peroxidase system with a non-carcinogenic chromogen. J Clin Pathol. 1969;22(2):158-161.

9. Allain CC, Poon LS, Chan CS, Richmond W, Fu PC. Enzymatic determination of total serum cholesterol. Clin Chem. 1974;20(4):470-475.

10. Fossati P, Prencipe L. Serum triglycerides determined colorimetrically with an enzyme that produces hydrogen peroxide. Clin Chem. 1982;28(10):2077-2080.

11. Lang PD, Schettler G. In: Schettler G, Gross R. Arteriosklerose, Grundlageon-Diagnosis-Therapie. Deustscher Arzte Verlag GmbH. Cologne/W. Germany: 1985.

12. Cheitlin MD, Armstrong WF, Aurigemma GP, Beller GA, Bierman FZ, Davis JL, Douglas PS, et al. ACC/AHA/ ASE 2003 guideline update for the clinical application of echocardiography: summary article: a report of the American College of Cardiology/American Heart Association Task Force on Practice Guidelines (ACC/AHA/ ASE Committee to Update the 1997 Guidelines for the Clinical Application of Echocardiography). Circulation. 2003;108(9):1146-1162.

13. Ryan TJ, Bauman WB, Kennedy JW, Kereiakes DJ, King SB, 3rd, McCallister BD, Smith SC, Jr., et al. Guidelines for percutaneous transluminal coronary angioplasty. A report of the American Heart Association/American College of Cardiology Task Force on Assessment of Diagnostic and Therapeutic Cardiovascular Procedures (Committee on Percutaneous Transluminal Coronary Angioplasty). Circulation. 1993;88(6):2987-3007.

14. Appropriate body-mass index for Asian populations and its implications for policy and intervention strategies. Lancet. 2004;363(9403):157-163.

15. Al Suwaidi J, Zubaid M, El-Menyar AA, Singh R, Rashed W, Ridha M, Shehab A, et al. Prevalence of the metabolic syndrome in patients with acute coronary syndrome in six middle eastern countries. J Clin Hypertens (Greenwich). 2010;12(11):890-899.

16. Danciu SC, Iqbal FM, Manankil FM, et al. Metabolic syndrome in younger patients with acute coronary syndrome. Eur J Gen Med. 2012;9(1):22-26.

17. Pandey S, Baral N, Majhi S, Acharya P, Karki P, Shrestha $\mathrm{S}$, Das BK, et al. Prevalence of the metabolic syndrome in acute myocardial infarction and its impact on hospital outcomes. Int J Diabetes Dev Ctries. 2009;29(2):52-55.

18. Yasar AS, Bilen E, Bilge M, Arslantas U, Karakas F. Impact of metabolic syndrome on coronary patency after thrombolytic therapy for acute myocardial infarction. Coron Artery Dis. 2009;20(6):387-391.

19. Dohi T, Miyauchi K, Kasai T, Kajimoto K, Kubota N, Tamura H, Yokoyama T, et al. Impact of metabolic syndrome on 10-year clinical outcomes among patients with acute coronary syndrome. Circ J. 2009;73(8):1454-1458.

20. Gupta A, Gupta R, Sarna M, Rastogi S, Gupta VP, Kothari K. Prevalence of diabetes, impaired fasting glucose and insulin resistance syndrome in an urban Indian popula- 
tion. Diabetes Res Clin Pract. 2003;61(1):69-76.

21. Ramachandran A, Snehalatha C, Satyavani K, Sivasankari S, Vijay V. Metabolic syndrome in urban Asian Indian adults - a population study using modified ATP III criteria. Diabetes Res Clin Pract. 2003;60(3):199-204.

22. Prasad SB, Fahrtash F, Malaiapan Y, Meredith IT, Cameron J. Obesity and the metabolic syndrome in patients with acute myocardial infarction. Int $\mathrm{J}$ Cardiol. 2010;144(3):450-451.

23. Takeno M, Yasuda S, Otsuka Y, Morii I, Kawamura A, Yano K, Miyazaki S. Impact of metabolic syndrome on the long-term survival of patients with acute myocardial infarction: potential association with C-reactive protein. Circ J. 2008;72(3):415-419.

24. Zeller M, Steg PG, Ravisy J, Laurent Y, Janin-Manificat L, L'Huillier I, Beer JC, et al. Prevalence and impact of metabolic syndrome on hospital outcomes in acute myocardial infarction. Arch Intern Med. 2005;165(10):11921198 .

25. Vikram NK, Pandey RM, Misra A, Sharma R, Devi JR, Khanna N. Non-obese (body mass index $<25 \mathrm{~kg} / \mathrm{m} 2$ ) Asian Indians with normal waist circumference have high cardiovascular risk. Nutrition. 2003;19(6):503-509.

26. Misra A, Wasir JS, Vikram NK. Waist circumference criteria for the diagnosis of abdominal obesity are not applicable uniformly to all populations and ethnic groups. Nutrition. 2005;21(9):969-976.

27. Mehta S, Mahajan D, Steinbeck KS, Bermingham MA. Relationship between measures of fatness, lipids and ethnicity in a cohort of adolescent boys. Ann Nutr Metab. 2002;46(5):192-199.

28. Gupta R, Prakash H, Kaul V. Cholesterol lipoproteins, triglycerides, rural-urban differences and prevalence of dyslipidaemia among males in Rajasthan. J Assoc Physicians India. 1997;45(4):275-279.
29. Gama R, Elfatih AB, Anderson NR. Ethnic differences in total and HDL cholesterol concentrations: Caucasians compared with predominantly Punjabi Sikh Indo-Asians. Ann Clin Biochem. 2002;39(Pt 6):609-611.

30. Babic Z, Pavlov M, Bulj N, Heitzler VN, Mitrovic V, Hamm C, Weber M. Metabolic syndrome and outcome in patients with acute myocardial infarction. Acta Clin Croat. 2011;50(2):193-199.

31. Pattnaik UK. Indian Scenario: Coronary Artery Disease. In: Das S, Ed. Complications of Diabetes in Indian Scenario. Proceedings Vol.I; 2000; p. 49-53.

32. Henry P, Makowski S, Richard P, Beverelli F, Casanova $\mathrm{S}$, Louali A, Boughalem K, et al. Increased incidence of moderate stenosis among patients with diabetes: substrate for myocardial infarction? Am Heart J. 1997;134(6): 10371043.

33. Melidonis A, Dimopoulos V, Lempidakis E, Hatzissavas J, Kouvaras G, Stefanidis A, Foussas S. Angiographic study of coronary artery disease in diabetic patients in comparison with nondiabetic patients. Angiology. 1999;50(12):997-1006.

34. Waldecker B, Waas W, Haberbosch W, Voss R, SteenMuller MK, Hiddessen A, Bretzel R, et al. Type 2 diabetes and acute myocardial infarction. Angiographic findings and results of an invasive therapeutic approach in type 2 diabetic versus nondiabetic patients. Diabetes Care. 1999;22(11):1832-1838.

35. Natali A, Vichi S, Landi P, Severi S, L'Abbate A, Ferrannini E. Coronary atherosclerosis in Type II diabetes: angiographic findings and clinical outcome. Diabetologia. 2000;43(5):632-641.

36. Dortimer AC, Shenoy PN, Shiroff RA, Leaman DM, Babb JD, Liedtke AJ, Zelis R. Diffuse coronary artery disease in diabetic patients: fact or fiction? Circulation. 1978;57(1):133-136. 